\title{
OnabotulinumtoxinA in the treatment of overactive bladder: a cost-effectiveness analysis versus best supportive care in England and Wales
}

\author{
Nick Freemantle ${ }^{1} \cdot$ Kristin Khalaf $^{2} \cdot$ Clara Loveman $^{3} \cdot$ Sanja Stanisic $^{4} \cdot$ \\ Dmitry Gultyaev ${ }^{5} \cdot$ Johanna Lister $^{5} \cdot$ Marcus Drake $^{6}$
}

Received: 16 September 2014/ Accepted: 29 September 2015/Published online: 19 October 2015

(C) The Author(s) 2015. This article is published with open access at Springerlink.com

\begin{abstract}
The cost-effectiveness of onabotulinumtoxinA $\left(\right.$ BOTOX $\left.^{\circledR}\right) 100 \mathrm{U}+$ best supportive care (BSC) was compared with BSC alone in the management of idiopathic overactive bladder in adult patients who are not adequately managed with anticholinergics. BSC included incontinence pads and, for a proportion of patients, anticholinergics and/or occasional clean intermittent catheterisation. A five-state Markov model was used to estimate total costs and outcomes over a 10-year period. The cohort was based on data from two placebo-controlled trials and a long-term extension study of onabotulinumtoxinA. After discontinuation of initial treatment, a proportion of patients progressed to downstream sacral nerve stimulation (SNS). Cost and resource use was estimated from a National Health Service perspective in England and Wales using relevant reference sources for 2012
\end{abstract}

Electronic supplementary material The online version of this article (doi:10.1007/s10198-015-0737-2) contains supplementary material, which is available to authorized users.

Nick Freemantle

nicholas.freemantle@ucl.ac.uk

1 Department of Primary Care and Population Health, UCL Medical School, Rowland Hill Street, London NW3 2PF, UK

2 Allergan Inc., 2525 Dupont Drive, Irvine, CA 92612-1599, USA

3 Allergan Holdings Ltd., Marlow International, The Parkway, Marlow SL7 1YL, UK

4 LA-SER ANALYTICA, Corso di Porta Nuova 34, Milan 20121, Italy

5 LA-SER ANALYTICA, Meeraner Platz 1, Lörrach 79539, Germany

6 School of Clinical Sciences and Bristol Urological Institute, University of Bristol, Southmead Road, Westbury-on-Trym, Bristol BS10 5NB, UK or 2013. Results showed that onabotulinumtoxinA was associated with lower costs and greater health benefits than BSC in the base case, with probabilistic sensitivity analysis indicating an $89 \%$ probability that the incremental cost-effectiveness ratio would fall below $£ 20,000$. OnabotulinumtoxinA remained dominant over BSC in all but two scenarios tested; it was also economically dominant when compared directly with SNS therapy. In conclusion, onabotulinumtoxinA appears to be a cost-effective treatment for overactive bladder compared with BSC alone.

Keywords Overactive bladder - OnabotulinumtoxinA . Incontinence $\cdot$ Cost-effectiveness

\section{JEL Classification I11}

\section{Introduction}

Overactive bladder $(\mathrm{OAB})$ is defined by the International Continence Society as urinary urgency, with or without urgency incontinence, usually with increased daytime frequency and nocturia, in the absence of other causes of similar symptoms $[1,2]$. OnabotulinumtoxinA (BOTOX ${ }^{\circledR}$, Allergan, Irvine, $\mathrm{CA}$ ) is a purified neurotoxin complex for the treatment of $\mathrm{OAB}$ with symptoms of urinary incontinence (UI), urgency and frequency in adults. It is recommended in many clinical guidelines, including those of the European Association of Urology [3], the American Urological Association [4] and the UK National Institute for Health and Care Excellence (NICE) [5], for patients whose UI symptoms are not managed adequately through behavioural changes or the use of anticholinergic medication. More than half of patients stop taking anticholinergic agents because of ineffectiveness, adverse events (AEs), or cost 
[6]. In the absence of onabotulinumtoxinA, patients may use best supportive care (BSC), including incontinence pads and, for some individuals, continuation of pharmacological therapies and occasional use of clean intermittent catheterisation (CIC), to manage their symptoms, or they may be candidates for more invasive therapies to manage $\mathrm{OAB}$ such as sacral nerve stimulation (SNS) or surgery [3].

The safety and efficacy of onabotulinumtoxinA in the management of idiopathic $\mathrm{OAB}$ in patients inadequately managed with anticholinergic medications was assessed in two double-blind, phase 3 trials (https://clinicaltrials.gov/, NCT00910520 and NCT00910845) with identical study designs $[7,8]$. In brief, both primary endpoints were met in the two pivotal trials. At week 12, patients treated with onabotulinumtoxinA experienced a significantly greater reduction in UI episodes than those who received a placebo saline injection $(-2.95$ vs -1.03 and -2.65 vs -0.87 , respectively; both $P<0.001)$, and a significantly greater proportion reported perceiving an improvement in symptoms since receipt of treatment (62.8 vs $26.8 \%$ and 60.8 vs $29.2 \%$, respectively; both $P<0.001)$. OnabotulinumtoxinA also provided a statistically significant benefit across secondary endpoints at week 12 compared with placebo, including urological and health-related quality of life outcomes. After 12 weeks, all individuals could request retreatment with onabotulinumtoxinA, and after 24 weeks patients became eligible to roll over directly into a longterm extension study (NCT00915525) [9], which will be completed in 2015.

To support these clinical data, we developed a model to estimate the cost-effectiveness of onabotulinumtoxinA compared with BSC, as cost-effectiveness data were not available in this population. A cost-effectiveness model was developed using pooled data from the phase 3 trials and the long-term extension trial to estimate the costs and outcomes of the use of onabotulinumtoxinA + BSC (hereafter, onabotulinumtoxinA) compared with BSC alone for the management of idiopathic $\mathrm{OAB}$ with symptoms of urge UI, urgency and frequency in adults who have an inadequate response to, or are intolerant of, an anticholinergic medication, over a 10-year period. The perspective is that of the NHS.

\section{Methods}

\section{Model structure}

A Markov decision-analytical model was developed to predict the long-term costs and health outcomes with onabotulinumtoxinA $100 \mathrm{U}$ compared with BSC. The Markov model was used to simulate transitions between health states in 3-month model cycles (MC) over a 10-year period (Fig. 1). Costs and outcomes were estimated for a cohort of

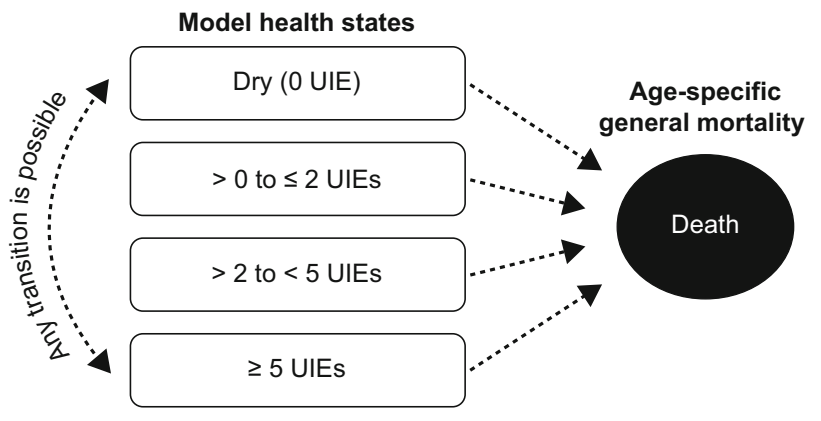

Fig. 1 Five-state Markov decision-analytical model. A patient can transition into an absorbing health state (dead, not shown) from any of the disability health states. UIE Urinary incontinence episode(s)

patients who entered the model at the time of the first treatment. A proportion of patients who stopped receiving onabotulinumtoxinA or BSC could transition to treatment with SNS (Fig. 2). The health states were defined by the daily number of UI episodes (Fig. 1): 0 episodes (i.e. dry); $>0$ to $\leq 2$ episodes; $>2$ to $<5$ episodes; and $\geq 5$ episodes.

The modelled cohort was based on pooled data from NCT00910520 and NCT00910845 $(n=1105)$ and an interim analysis of the long-term extension trial $(n=825)$ conducted after 1 year. These were multinational in design and included centres in the UK. At baseline, the mean age was 60.4 years, $87.8 \%$ of participants were women and the mean [standard deviation (SD)] number of UI episodes per day was 5.4 (3.6); these patients were considered representative of the eligible patient population in the UK. At baseline and for MC 1, the distribution of patients across health states observed in the trials was applied to the model (Table 1). BSC data were derived from patients who received a saline injection in place of onabotulintoxinA; however, because randomisation was not maintained after week 12 , owing to crossover to onabotulinumtoxinA, no transition probabilities were applied at MC 2 or beyond and it was assumed that individuals would remain in the health state they were in at the end of MC 1 for the duration of the time horizon modelled. By contrast, patients receiving onabotulinumtoxinA could transition between any health state in each MC. Transition probabilities were derived from the pooled trial data by averaging UI episodes by MC. For MC 2-4, transitions were calculated for patients who were randomised to onabotulinumtoxinA and the mean transition probability was applied to each MC (Online Resource 6). To extend the time horizon beyond 1 year, an average of the transition probabilities for MC 2-4 was applied to each MC from MC 5 onwards; this extrapolation used data only from patients who remained on onabotulinumtoxinA for at least 12 months (corresponding to MC 4) (Online Resource 6).

Patients could request retreatment after 12 weeks in the pivotal trials if they had $\geq 2$ urgency UI episodes per day. 


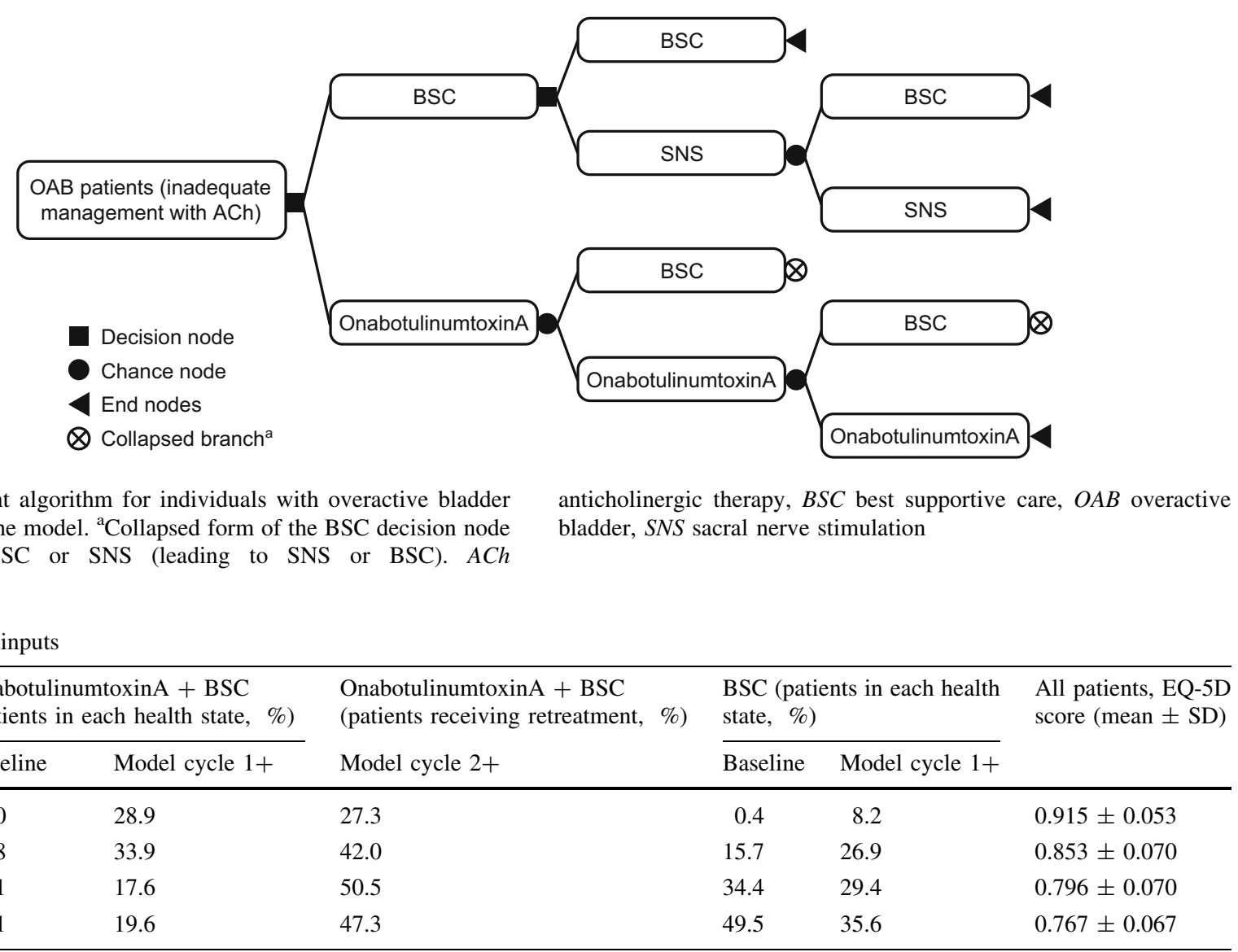

Fig. 2 Treatment algorithm for individuals with overactive bladder $(\mathrm{OAB})$ used in the model. ${ }^{\mathrm{a}}$ Collapsed form of the BSC decision node followed by BSC or SNS (leading to SNS or BSC). ACh

anticholinergic therapy, $B S C$ best supportive care, $O A B$ overactive bladder, SNS sacral nerve stimulation

Table 1 Model inputs

\begin{tabular}{lllllll}
\hline UIE/day & $\begin{array}{l}\text { OnabotulinumtoxinA + BSC } \\
\text { (patients in each health state, } \%)\end{array}$ & $\begin{array}{l}\text { OnabotulinumtoxinA + BSC } \\
\text { (patients receiving retreatment, \%) }\end{array}$ & \multicolumn{2}{l}{$\begin{array}{l}\text { BSC (patients in each health } \\
\text { state, \%) }\end{array}$} & $\begin{array}{l}\text { All patients, EQ-5D } \\
\text { score (mean } \pm \text { SD) }\end{array}$ \\
\cline { 2 - 3 } & Baseline & Model cycle 1+ & & Model cycle 2+ & Baseline & Model cycle 1+ \\
\hline Dry & 0.0 & 28.9 & 27.3 & 0.4 & 8.2 & $0.915 \pm 0.053$ \\
$>0$ to $\leq 2$ & 17.8 & 33.9 & 42.0 & 15.7 & 26.9 & $0.853 \pm 0.070$ \\
$>2$ to $<5$ & 35.1 & 17.6 & 50.5 & 34.4 & 29.4 & $0.796 \pm 0.070$ \\
$\geq 5$ & 47.1 & 19.6 & 47.3 & 49.5 & 35.6 & $0.767 \pm 0.067$ \\
\hline
\end{tabular}

$B S C$ best supportive care, $E Q-5 D$ EuroQol-5 dimension, UIE urinary incontinence episodes, $S D$ standard deviation

The median time for patients to receive their first retreatment was 26.6 weeks. A total of $66.7 \%$ of onabotulinumtoxinA patients were retreated in the 1 st year. The proportion of patients who received retreatment during each MC was applied over year 1, averaged across MC 2-4, and applied to MC 5 and onwards. Discontinuation from onabotulinumtoxinA was modelled using a criterion that patients with $<50 \%$ reduction in UI episodes from baseline after two consecutive treatments would discontinue treatment in the 1 st year. The proportion of patients remaining in the onabotulinumtoxinA arm at the end of year 1 was $78.3 \%$. Thereafter, a discontinuation rate of $1.4 \%$ per MC was used based on a retrospective study that followed 125 patients with OAB who received onabotulinumtoxinA over a 5-year period [10]. These assumptions broadly agree with the results from a small UK study, in which most discontinuations occurred after the second administration of onabotulinumtoxinA, with few discontinuations thereafter [11].

\section{Adverse events}

The two most common AEs reported in the trials NCT00910520 and NCT0910845 were urinary tract infection (UTI; 20.4 and $15.5 \%$ of patients receiving onabotulinumtoxinA, respectively) and urinary retention (5.8 and $5.4 \%$ respectively), and these were included in the model by $\mathrm{MC}$ and by treatment arm (Online Resource 1) [7, 8]. Urinary retention led to CIC in $6.9 \%$ and $6.1 \%$ of onabotulinumtoxinA-treated patients in each of the trials, respectively. Rare AEs $(\leq 3 \%)$ reported during the first 12 weeks of NCT00910520 and NCT0910845, or those considered to be part of a UTI such as dysuria (5.8 and $12.2 \%$ respectively) and bacteriuria (3.6 and $5.0 \%$ respectively), were not input into the model because they would have insignificant impact on the model results.

\section{Utilities}

The Incontinence Quality of Life (I-QOL) questionnaire was administered in the pivotal trials to capture the impact of UI on patients' lives. Utility values used for the basecase analysis were derived from EuroQol-5 dimension (EQ-5D) values, which were calculated from the I-QOL through application of a pre-existing mapping algorithm developed from an international sample of 2351 patients with idiopathic OAB using the EQ-5D UK tariff [12]. 
The EQ-5D utilities were incorporated into the model by health state, so that each state was assigned a utility value derived from the average of all EQ-5D values for patients (months 0-12) in the pooled study population (Table 1). The EQ-5D values were selected for the base-case analysis in line with the preference of the UK Health Technology Assessment agencies. In scenario analyses, Short Form-6 dimension (SF-6D) utility values were also estimated from the Short Form-12 version 2 (SF-12v2) administered in the trial [13] as well as calculated directly from the I-QOL, using a preference-based index developed from valuation of disease-specific health states in a sample of UK adults (the Incontinence Utility Index [IUI]) [14]. These utility values are presented in Online Resource 4.

There were no trial data or published values to provide utility estimates around the use of SNS appropriate for the health states in this model. To overcome this, patients with a successful SNS test or implant (defined as $\geq 50 \%$ reduction in UI episodes) were assumed to have the same utility values as patients who received onabotulinumtoxinA at MC 1. Among those who did not respond to the SNS test or implant, the utility associated with the health state before SNS was applied. Similarly, there were no published data to inform estimates of disutility associated with AEs. A $5 \%$ reduction in utility was applied to all patients who either experienced a UTI or used CIC, and the utility decrement lasted for 5 days, in line with previous studies $[15,16]$. Applying an additional decrement was considered a potentially conservative approach because the impact of AEs might have been captured by the I-QOL. No disutility was associated with SNS test or implant procedures.

\section{Resource use and cost}

The model incorporated costs of treatment, administration, follow-up and management of AEs, from the NHS perspective in England and Wales, using relevant reference sources for 2012 or 2013. Resource use and costs are described in Tables 2 and 3, respectively. OnabotulinumtoxinA was administered in the hospital outpatient setting; the cost of administration included a prophylactic course of antibiotics. In the month before retreatment, it was assumed that $15 \%$ of patients receiving onabotulinumtoxinA would be prescribed an anticholinergic [17]. Of the patients who received BSC, $60 \%$ used anticholinergic therapy continuously. The cost of anticholinergics was based on a mix of branded and generic medication derived from UK retail (British Pharmaceutical Index) and hospital (Hospital Pharmacy Audit) data (unpublished). Patients receiving either onabotulinumtoxin A or BSC visited their physician at a frequency determined by the health state, irrespective of treatment received. These frequencies were based on a recent international burden of illness study, which assessed resource use across subgroups of patients determined by frequency of UI episodes [18]. Both treatment groups used incontinence pads and it was assumed that all incontinence pads were reimbursed and were used at a rate of one pad per UI episode, based on expert advice (Table 3). The cost of managing AEs comprised the costs of a primary care physician consultation and a 3-day course of trimethoprim per episode of UTI. The cost of treating urinary retention was calculated based on the cost of catheter use for those requiring CIC, taking frequency and duration of CIC into account based on clinical trial data from NCT00910520 and NCT0910845 (CIC rates of $6.9 \%$ and $6.1 \%$, respectively). No costs were included for urodynamic testing for individuals receiving either onabotulinumtoxinA or BSC because such testing procedures are standard in this patient population and independent of the choice of subsequent treatment $[3,5]$.

The use of SNS was modelled using data from available guidelines or, failing that, using weighted averages derived from a literature review. It was assumed that $29.7 \%$ of patients who stopped or were not successfully managed with onabotulinumtoxinA or BSC underwent SNS treatment based on findings from the East Midlands Specialised Commissioning Group (2012), (the only group to report such data) [19]. Following the NICE guideline for the management of UI in women (CG171) [5, 20] SNS was initiated 3 months after discontinuing treatment with onabotulinumtoxinA or BSC. Patients underwent testing before receiving an SNS implant, using a one-stage percutaneous nerve evaluation (PNE) comprising a tined lead and a temporary electrode with an external battery. Patients with a successful test received a one-stage SNS modulator implant, comprising an implanted battery connected to the same lead. Two-stage PNE tests and implants are used less widely and costs for these were therefore not included [5, 20]. Temporary PNE electrodes were removed in all patients who did not respond in the testing phase (based on NICE Guidelines) [5, 20]. It was assumed that $7 \%$ of patients who did not respond to SNS would have the device explanted [21-26], and that among those who did respond, $23 \%$ would undergo surgical revision [21, 23-27]. It was assumed that individuals would have three physician visits for SNS device programming per year [28]. The SNS batteries were replaced approximately every 7 years [5].

In one scenario analysis, the cost-effectiveness of SNS was compared directly with that of onabotulinumtoxinA. In the absence of randomised head-to-head trial data, this scenario used the same methodology previously applied to model SNS as a downstream treatment option. The distribution across health states of patients undergoing SNS after successful implantation was based on the equivalent distribution of the onabotulinumtoxinA cohort. 
Table 2 Resource use inputs for the Markov model

\begin{tabular}{|c|c|c|}
\hline Parameter & Input & Reference \\
\hline \multirow{2}{*}{$\begin{array}{l}\text { Anticholinergic use as part of BSC (proportion of patients). } \\
\text { Anticholinergic use before onabotulinumtoxinA + BSC retreatment } \\
\text { (proportion of patients) }\end{array}$} & $60 \%$ & Assumption based on clinical opinion \\
\hline & $15 \%$ & Assumption from the literature [17] \\
\hline $\begin{array}{l}\text { Duration of anticholinergic use before onabotulinumtoxinA + BSC } \\
\text { retreatment }\end{array}$ & 1 month & Assumption from the literature [17] \\
\hline Number of incontinence pads per UI episode & 1 pad & Assumption \\
\hline Proportion of patients who have pads reimbursed & $100 \%$ & Assumption \\
\hline \multicolumn{3}{|c|}{ Physician visits for patients treated with onabotulinumtoxinA or BSC per month by health state (mean \pm SD) } \\
\hline Dry & $0.20 \pm 0.02$ & Cost of disease study [18] \\
\hline$>0$ to $\leq 2 \mathrm{UIE} /$ day & $0.30 \pm 0.03$ & \\
\hline$>2$ to $<5 \mathrm{UIE} /$ day & $0.38 \pm 0.04$ & \\
\hline$\geq 5 \mathrm{UIE} /$ day & $0.60 \pm 0.06$ & \\
\hline $\begin{array}{l}\text { Proportion of patients undergoing SNS treatment after discontinuing } \\
\text { onabotulinumtoxinA }+ \text { BSC or BSC }\end{array}$ & $29.7 \%$ & \multirow{3}{*}{$\begin{array}{l}\text { East Midlands Specialised Commissioning } \\
\text { Group [19]. Weighted average calculated } \\
\text { from literature review [21-26]. Weighted } \\
\text { average calculated from literature review } \\
\text { [21-26] }\end{array}$} \\
\hline Proportion of patients with a successful SNS test & $51.1 \%$ & \\
\hline Proportion of patients with a successful implant & $69.2 \%$ & \\
\hline Time to initiation of SNS & 3 months & Assumption based on NICE CG171 [20] \\
\hline Proportion of SNS patients with removed temporary PNE electrodes & $100 \%$ & NICE CG171 and expert opinion [20] \\
\hline Proportion of SNS patients with explanted device & $7.1 \%$ & \multirow{2}{*}{$\begin{array}{l}\text { Weighted average calculated from literature } \\
\text { review [21-26]. Weighted average } \\
\text { calculated from literature review [21-27] }\end{array}$} \\
\hline $\begin{array}{l}\text { Proportion of patients with successful SNS undergoing surgical } \\
\text { revision }\end{array}$ & $23.3 \%$ & \\
\hline $\begin{array}{l}\text { Additional physician visits associated with device programming } \\
\text { (per year) }\end{array}$ & 3 & NHS England [28] \\
\hline
\end{tabular}

$B S C$ best supportive care, $C G$ clinical guideline, NHS National Health Service, NICE National Institute for Health and Care Excellence, PNE percutaneous nerve evaluation, SNS sacral nerve stimulation, UI urinary incontinence, UIE urinary incontinence episodes

\section{Economic analysis}

To estimate costs and benefits over the time frame of the model, the number of patients in each health state at each cycle was multiplied by costs and utilities associated with the relevant health state. A $3.5 \%$ annual discount rate was applied to both costs and benefits [29]. The incremental cost per quality-adjusted life-year (QALY) gained [the incremental cost-effectiveness ratio (ICER)] was calculated.

Pre-specified scenario analyses were used to examine the impact of changes to key assumptions: reducing the time frame of the analysis to 3 or 5 years; varying the discount rate to $0 \%$ or $6 \%$; considering a female-only population; using SF-12 and I-QOL IUI to estimate utilities; using the number of UI episodes at baseline for patients given placebo saline injections to model BSC; removing anticholinergic use; increasing the cost of administration; and including SNS as a direct comparator of onabotulinumtoxinA. Deterministic sensitivity analysis was used to explore uncertainty concerning individual input values to the model, with model parameters varied over a plausible range determined by the standard error or, if this was not available, by $\pm 10 \%$ of the point estimate.
In addition, utility values, number of UI episodes and frequency of follow-up visits were tested by multi-way analysis such that values were changed simultaneously across health states to derive total minimum and maximum ICERs. Parameters with the greatest effect on the ICER (i.e. those that changed the ICER by more than $10 \%$ ) were included in the tornado diagram (Fig. 3). In addition, probabilistic sensitivity analyses were used to assess the overall level of uncertainty in the model via repeated sampling from each parameter's distribution using the Monte Carlo method [30] (Online Resources 2 and 3 for distributions and ranges).

\section{Results}

\section{Base case}

In the base-case analysis, onabotulinumtoxinA was associated with greater benefit and lower cost than BSC, and was therefore the economically dominant treatment option (Table 4). The total discounted cost per patient over the 10 -year period was $£ 10,160$ with onabotulinumtoxinA and $£ 11,572$ with BSC. Total QALYs were 6.908 with 
Table 3 Cost inputs for the Markov model

\begin{tabular}{|c|c|c|}
\hline Parameter & $\begin{array}{l}\text { Input } \\
(\mathfrak{L})\end{array}$ & Reference \\
\hline OnabotulinumtoxinA (100 U vial) & 138.20 & BNF [46] \\
\hline $\begin{array}{l}\text { Anticholinergics (per patient per } \\
\text { month) }\end{array}$ & 28.31 & $\begin{array}{l}\text { Average monthly cost based on market share of generic and branded anticholinergics, } \\
\text { Allergan [data on file] and BNF [46] }\end{array}$ \\
\hline Antibiotics (per course) & 0.59 & $\mathrm{BNF}^{\mathrm{a}}[46]$ \\
\hline Incontinence pads (per pad) & 0.25 & NHS supply chain \\
\hline Catheters for CIC (per catheter) & 0.75 & NHS supply chain \\
\hline Onabotulinumtoxin $\mathrm{A}$ administration $^{\mathrm{b}}$ & 219.00 & HRG tariff LB17Z code for hospital outpatient [47] \\
\hline Specialist physician visit & 102.00 & National Schedule of Reference Costs [48] \\
\hline Physician visit to treat UTI & 63.00 & Unit costs of health and social care, PSSRU [49] \\
\hline Removal of temporary SNS electrodes & 1166.00 & $\begin{array}{l}\text { Estimate from NICE CG171: nurse-led visit ( } £ 70 \text {-non-consultant-led face-to-face } \\
\text { outpatient-PSSRU 2011); explants procedure ( } £ 1096, \text { HRG code AA21Z—but may be } \\
\text { less because this is a small procedure) [20] }\end{array}$ \\
\hline PNE test (one-stage test) & 1485.00 & \multirow{2}{*}{$\begin{array}{l}\text { Estimate from NICE CG171. Costs based on estimate from NICE CG171: implantation } \\
\text { (£2441, HRG code AB01Z, complex neurological pain procedure); patient controlled } \\
\text { programmer ( } £ 500, \text { NHS, checked by Medtronic, 2012); implantable pulse generator } \\
(£ 5700, \text { NHS, checked by Medtronic, } 2012)[20]\end{array}$} \\
\hline $\begin{array}{l}\text { One-stage SNS implant (electrode and } \\
\text { modulator implants) }\end{array}$ & 8641.00 & \\
\hline SNS device explant & 923.00 & \multirow{2}{*}{$\begin{array}{l}\text { OPCS-4 code (A70.2 Removal of neurostimulator in peripheral nerve) [20, 50]. Maintenance } \\
\text { of neurostimulator. Day case/elective inpatient HRG tariff: AB04Z major pain procedures } \\
\text { A70.2 maintenance of neurostimulator in peripheral nerve }[20,47]\end{array}$} \\
\hline SNS surgical revision & 592.00 & \\
\hline SNS battery replacement & 6623.00 & $\begin{array}{l}\text { Based on estimate from NICE CG171: device ( } £ 5700-\text { NICE CG171 does not provide } \\
\text { further information); replacement ( } £ 923-\text { HRG A70.2 maintenance of neurostimulator in } \\
\text { peripheral nerve) [20] }\end{array}$ \\
\hline SNS follow-up physician visit & 319.00 & Neurosurgical consultation WF01B OP Code 150 First Attendance-Single Professional [51] \\
\hline
\end{tabular}

BNF British National Formulary, $C G$ clinical guideline, $C I C$ clean intermittent catheterisation, $H R G$ Healthcare Resource Group, NHS National Health Service, NICE National Institute for Health and Care Excellence, OPCS-4 Office of Population, Censuses and Surveys Classification of Surgical Operations and Procedures (4th revision), PNE percutaneous nerve evaluation, PSSRU Personal Social Services Research Unit, SNS sacral nerve stimulation, UTI urinary tract infection

${ }^{\mathrm{a}}$ UTI per-patient per-episode medication costs BNF 64, trimethoprim $200 \mathrm{mg}$ twice daily (adults) $=(82 / 14 \mathrm{p}) \times 2=11.71 \mathrm{p} / \mathrm{day} \times$ 5 days $=58.57 \mathrm{p}$

b LB17Z is the introduction of therapeutic substance into the bladder, as admitted care or outpatient procedure. This includes prophylactic use of antibiotics before the intervention

onabotulinumtoxinA and 6.695 with BSC. The main cost savings with onabotulinumtoxinA were from less downstream SNS therapy (-£2188), fewer incontinence pads $(-£ 1214)$ and fewer physician visits $(-£ 858)$ than with BSC (Online Resource 5).

\section{Sensitivity analyses}

Probabilistic sensitivity analysis from sampling the basecase parameter distributions suggested that there was an $89 \%$ likelihood that the ICER was below $£ 20,000$. The shape of the cost-effectiveness acceptability curve was relatively flat around the $£ 20,000$ willingness-to-pay threshold, indicating that the probability of onabotulinumtoxinA being cost-effective remains reasonably consistent around this threshold (Fig. 4, scatter plot shown in Online Resource 7).

OnabotulinumtoxinA remained dominant over BSC across most scenarios tested (Table 5). Changing the utilities did not qualitatively affect the results; however, the QALY gain with onabotulinumtoxinA compared with BSC was somewhat smaller using utilities derived from the SF-12 instrument (0.130) and larger using the IUI (0.569) compared with the EQ-5D utilities used in the base case (0.213). OnabotulinumtoxinA was also found to be economically dominant when compared directly with SNS therapy (incremental cost: $-£ 6668$; incremental QALYs gained: 0.144) and when a female-only population was considered. There were two non-dominant scenarios: when SNS was not included as a downstream treatment (the ICER was £2369) and when the cost of onabotulinumtoxinA administration was increased to $£ 449$ (the ICER was $£ 3310$ ).

The tornado diagram (Fig. 3) indicated that the ICER was most sensitive to the frequency of UTIs. Increasing the estimated frequency of UTIs from 0 to 2.65 events per patient per 3-month cycle in the onabotulinumtoxinA arm led to an ICER of $£ 4133 / \mathrm{QALY}$. The ICER was also sensitive to the daily number of UI episodes. 


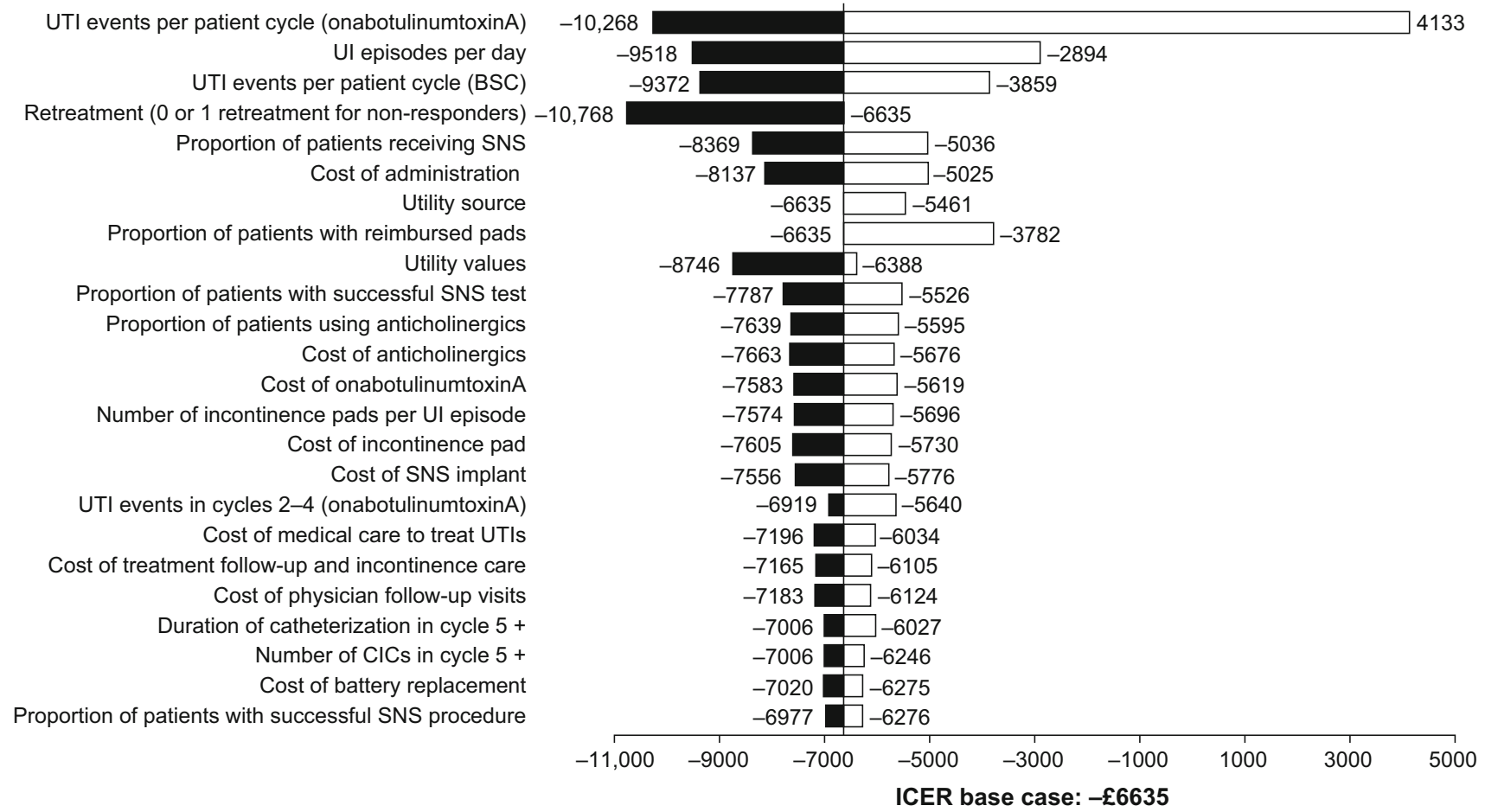

Fig. 3 Outcomes of the one-way sensitivity analysis, showing the effect of changing individual parameters on the ICER (10-year time horizon). BSC best supportive care, CIC clean intermittent catheterisation, ICER incremental cost-effectiveness ratio, SNS sacral nerve stimulation, UI urinary incontinence, UTI urinary tract infection

Table 4 Results for the base-case analysis for costs and effects discounted at $3.5 \%$ over the 10-year time horizon

\begin{tabular}{llllllr}
\hline & Treatment group & Total costs $(£)$ & QALYs & Incremental cost & Incremental QALYs & ICER \\
\hline Deterministic & OnabotulinumtoxinA & 10,160 & 6.908 & $-£ 1412$ & 0.213 & Dominant \\
& BSC & 11,572 & 6.695 & & 0.152 & Dominant \\
Probabilistic & OnabotulinumtoxinA & 10,244 & 6.838 & $-£ 1341$ & & \\
& BSC & 11,585 & 6.687 & & \\
\hline
\end{tabular}

$B S C$ best supportive care, ICER incremental cost-effectiveness ratio, $Q A L Y$ quality-adjusted life-year

\section{Discussion}

The cost-effectiveness model showed that, in the base-case deterministic analysis, onabotulinumtoxinA $100 \mathrm{U}$ was economically dominant over BSC for the management of $\mathrm{OAB}$ with symptoms of urge UI, urgency and frequency in adults who have an inadequate response to, or are intolerant of, an anticholinergic medication. Economic dominance was achieved through the higher probability of experiencing a reduction in the number of UI episodes with onabotulinumtoxinA than with BSC. Reduction in the frequency of UI episodes was associated with decreased healthcare resource utilisation, particularly the use of incontinence pads, and with lower overall costs and increased quality of life. When uncertainty was taken into account via a probabilistic sensitivity analysis, there was an
$89 \%$ probability that the ICER was below $£ 20,000$ - a commonly accepted threshold for cost-effectiveness in the UK for non-cancer treatments [31]. The relatively flat curve for the probabilistic analysis around the $£ 20,000$ willingness-to-pay threshold indicates a consistent probability of therapy being cost-effective around this threshold. Although there is a previously published economic evaluation of onabotulinumtoxinA $100 \mathrm{U}$ for the treatment of idiopathic OAB [32], this is the first study that incorporates phase 3 data in line with the newly approved indication [33].

The model was based on the pivotal trials of onabotulinumtoxinA in OAB [7, 8]. Although the model followed the clinical trials as closely as possible, some modifications were made to incorporate practical aspects of treating patients with $\mathrm{OAB}$ that were not part of the trial 


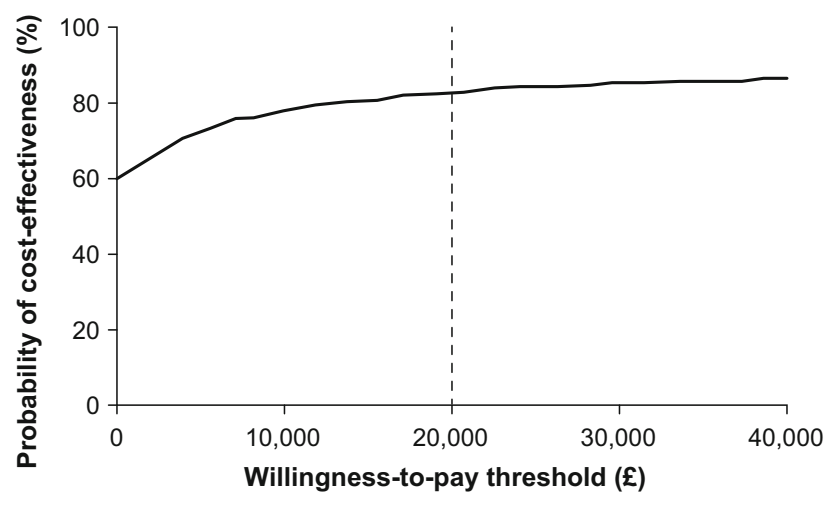

Fig. 4 Probabilistic sensitivity analysis of onabotulinumtoxin A + BSC vs BSC alone for the treatment of OAB using an NHS perspective in England and Wales. BSC best supportive care, $N H S$ National Health Service, $O A B$ overactive bladder

design, including the use of anticholinergic medication. In the trials, patients were not able to use anticholinergic medications, but in clinical practice patients often continue using anticholinergics as part of BSC, despite the symptoms of $\mathrm{OAB}$ being inadequately managed with these drugs. The reduction in OAB symptoms experienced among individuals randomised to placebo saline injections was included in the model as a proxy for any potential efficacy for anticholinergics. This was modelled conservatively as the effect at MC 1 was assumed to last for the duration of the model (with no further transition probabilities applied in the BSC group).

A key area of uncertainty in cost-utility models is the source of utility estimates. Valuing states of health for economic evaluation has often been accomplished using generic preference-based instruments such as the EQ-5D, SF-6D and others. However, these instruments may produce substantially different values for the same health states, and their ability to discriminate between individuals whose health states are known to differ and to detect a known change in an individual's health state may be limited [34-38]. Deriving a condition-specific preference

Table 5 Results from the scenario analyses

\begin{tabular}{|c|c|c|c|c|c|c|}
\hline \multirow[t]{2}{*}{ Scenario } & \multirow[t]{2}{*}{ Treatment } & \multicolumn{2}{|l|}{ Total } & \multicolumn{3}{|c|}{ Incremental } \\
\hline & & Cost $(\mathfrak{£})$ & QALYs & Cost $(\mathfrak{f})$ & QALYs & ICER \\
\hline \multirow[t]{2}{*}{ 3-year time horizon } & OnabotulinumtoxinA & 3801 & 2.415 & -1442 & 0.086 & Dominant \\
\hline & $\mathrm{BSC}$ & 5243 & 2.329 & & & \\
\hline \multirow[t]{2}{*}{ 5-year time horizon } & OnabotulinumtoxinA & 5860 & 3.856 & -1243 & 0.133 & Dominant \\
\hline & BSC & 7103 & 3.724 & & & \\
\hline \multirow[t]{2}{*}{ Discount rate: $0 \%$ (costs and effects) } & OnabotulinumtoxinA & 11,702 & 7.997 & -1426 & 0.243 & Dominant \\
\hline & BSC & 13,128 & 7.755 & & & \\
\hline \multirow[t]{2}{*}{ Discount rate: $6 \%$ (costs and effects) } & OnabotulinumtoxinA & 9266 & 6.276 & -1406 & 0.195 & Dominant \\
\hline & BSC & 10,671 & 6.081 & & & \\
\hline \multirow[t]{2}{*}{ No downstream SNS } & Onabotulinumtoxin A & 9910 & 6.906 & 565 & 0.239 & $£ 2369$ \\
\hline & BSC & 9344 & 6.667 & & & \\
\hline \multirow[t]{2}{*}{ Female-only population } & OnabotulinumtoxinA & 10,455 & 6.979 & -1428 & 0.229 & Dominant \\
\hline & BSC & 11,883 & 6.751 & & & \\
\hline \multirow[t]{2}{*}{ SF-12 utilities } & OnabotulinumtoxinA & 10,160 & 5.683 & -1412 & 0.130 & Dominant \\
\hline & BSC & 11,572 & 5.553 & & & \\
\hline \multirow[t]{2}{*}{ I-QOL utilities } & OnabotulinumtoxinA & 10,160 & 3.105 & -1412 & 0.569 & Dominant \\
\hline & BSC & 11,572 & 2.536 & & & \\
\hline \multirow[t]{2}{*}{ BSC, UI episodes at baseline throughout } & OnabotulinumtoxinA & 10,397 & 6.855 & -911 & 0.305 & Dominant \\
\hline & BSC & 11,308 & 6.550 & & & \\
\hline \multirow[t]{2}{*}{ Removal of concomitant anticholinergic use } & OnabotulinumtoxinA & 9941 & 6.908 & -125 & 0.213 & Dominant \\
\hline & BSC & 10,066 & 6.695 & & & \\
\hline \multirow[t]{2}{*}{ Increased cost of onabotulinumtoxin $\mathrm{A}$ administration ${ }^{\mathrm{a}}$} & OnabotulinumtoxinA & 12,276 & 6.908 & 704 & 0.213 & $£ 3310$ \\
\hline & BSC & 11,572 & 6.695 & & & \\
\hline \multirow[t]{2}{*}{ Direct comparison with SNS } & OnabotulinumtoxinA & 10,160 & 6.908 & -6668 & 0.144 & Dominant \\
\hline & SNS & 16,828 & 6.764 & & & \\
\hline
\end{tabular}

$B S C$ best supportive care, ICER incremental cost-effectiveness ratio, $I-Q O L$ Incontinence Quality of Life, $Q A L Y$ quality-adjusted life-year, $S F-12$ Short Form-12, SNS sacral nerve stimulation, UI urinary incontinence

a Cost of administration increased to $£ 449$, from tariff LB14E (bladder intermediate endoscopic procedure 19 years and over, 2012-2013 tariff, admitted care and outpatient procedures) 
index de novo or from an existing condition-specific health measure is one approach to address these limitations. Because of this uncertainty, three different utility sources were used to test the robustness of results in the model. EQ$5 \mathrm{D}$ index values were used in the base case [38]. The estimated EQ-5D utility difference of $0.15(0.92-0.77)$ between the dry health state and the $\geq 5$ UI episodes per day health state is consistent with previous evidence, including the NICE guideline for UI in women [utility difference of $0.11(0.85-0.74)$ ] [5] as well as with earlier economic evaluations in $\mathrm{OAB}[15,32]$. Utilities were also estimated directly from the condition-specific I-QOL [39] as well as from the SF-12v2 (IUI and SF-6D utilities) [13, 14], and evaluated in scenario analysis. Utilities directly elicited from the I-QOL tool gave the largest QALY differential in favour of onabotulinumtoxinA (0.57), with utilities from the generic SF-12 giving the smallest difference (0.13). The QALY differential with the EQ-5D utilities $(0.21)$ was closer to the SF-12v2 estimate than to the I-QOL estimate. Despite the variability seen across utility sources, cost-effectiveness results remained consistent and across each utility source tested, onabotulinumtoxinA remained dominant over BSC.

Scenario analysis was used to assess the cost-effectiveness of onabotulinumtoxinA when compared directly with SNS. This scenario was included as it is potentially relevant in some referral centres in England, in which a decision is made between treatment with SNS and onabotulinumtoxinA. In the current analysis, onabotulinumtoxinA was dominant over SNS. This broadly agrees with the recent NICE analysis, in which the strategy of providing onabotulinumtoxinA to eligible women was more likely to be cost-effective, at the $£ 20,000$ threshold, than the strategy of providing SNS first [20].

For two scenario analyses, onabotulinumtoxinA was no longer dominant over BSC. The first was when SNS was not included as a downstream treatment. In the base case, a larger proportion of patients treated with BSC than those treated with onabotulinumtoxinA did not achieve an adequate response to therapy and were therefore eligible to receive SNS therapy. Removal of SNS from the treatment pathway eliminated the associated downstream costs, which resulted in greater savings in the BSC group. This led to a non-dominant but still cost-effective ICER in favour of onabotulinumtoxinA. Although this analysis shows that the inclusion of SNS makes no qualitative difference to the finding that onabotulinumtoxinA is a costeffective therapy in this indication, SNS is a viable treatment option after failure of initial therapies and it is therefore warranted to include it somewhere in the treatment pathway.

The second non-dominant scenario resulted when the administration cost of onabotulintoxinA was increased (doubled) from $£ 219$ to $£ 449$ to account for any variation in tariff used in the NHS [20]. However, the ICER remained cost-effective even after this increase in cost. The tornado diagram showed that the model was also sensitive to the incidence of UTI in the onabotulinumtoxinA arm, and to the number of UI episodes.

One limitation of the model is that costs and health outcomes arising from the long-term consequences of poorly managed OAB and UI were not included. These might include damage to the skin from prolonged contact with urine [40, 41], possible fractures and injuries from falls [42, 43], and increased mortality associated with $O A B$ in elderly patients [44]. If these data become available, they could be incorporated into an updated model. A second limitation is that the results from some investigator-led onabotulinumtoxinA studies, with follow-up of up to 8 years, could not be included in the analysis [17]. Although discontinuation rates were modelled using a retrospective analysis with a median follow-up of 38 months [10], other studies were not included because of differences in study design (e.g. different dose of onabotulinumtoxinA, non-randomised study design and a different patient population) that would prevent meaningful comparison with the clinical trial data. The current model used long-term data from the second interim analysis of the ongoing long-term extension study (cut-off date 15 May 2012). A third limitation is that the model does not include treatment with the new oral pharmacological agent mirabegron. This was not included as mirabegron was unlicensed when the model was being developed and did not have an established clinical profile. A fourth limitation is that, as with any RCT, the pivotal trials from which the model data were derived were designed to have the internal validity required to establish efficacy and safety, but may not have the external validity needed to demonstrate "real world" effectiveness. In order to mitigate this limitation, we used interim efficacy data from the open-label, longterm extension study in our model [9]. In addition, realworld studies have corroborated the efficacy and safety results observed in the pivotal trials [45].

This economic evaluation is expected to be generalisable to other healthcare systems. Although this economic evaluation used costs and resource use specific to England and Wales, and costs differ substantially across countries, the overall model structure is in accordance with international OAB treatment guidelines $[3,4,20]$.

In summary, this study has demonstrated that onabotulinumtoxinA is cost-effective compared with both BSC and SNS for the treatment of OAB in patients who were not managed adequately with anticholinergic medication.

Acknowledgements The authors take full responsibility for the content of the manuscript but would like to thank Dr. Polly Field and 
Sophie Shina from Oxford PharmaGenesis for editorial support in developing the manuscript. This project was funded by Allergan Inc. Nick Freemantle has received funding for research and consulting from Allergan and Ipsen. Kristin Khalaf and Clara Loveman are employees of Allergan. Sanja Stanisic, Dmitry Gultyaev and Johanna Lister are employees of LA-SER ANALYTICA who received funding from Allergan. Marcus Drake has received funding for research and consulting from Allergan, Apogepha, Astellas, Ferring and Pfizer.

Open Access This article is distributed under the terms of the Creative Commons Attribution 4.0 International License (http://crea tivecommons.org/licenses/by/4.0/), which permits unrestricted use, distribution, and reproduction in any medium, provided you give appropriate credit to the original author(s) and the source, provide a link to the Creative Commons license, and indicate if changes were made.

\section{References}

1. Abrams, P., Cardozo, L., Fall, M., Griffiths, D., Rosier, P., Ulmsten, U., van Kerrebroeck, P., Victor, A., Wein, A.: The standardisation of terminology of lower urinary tract function: report from the Standardisation Sub-committee of the International Continence Society. Neurourol. Urodyn. 21, 167-178 (2002)

2. Drake, M.J.: Do we need a new definition of the overactive bladder syndrome? Neurourol. Urodyn. 33, 622-624 (2014)

3. Lucas, M.G., Bosch, R.J., Burkhard, F.C., Cruz, F., Madden, T.B., Nambiar, A.K., Neisius, A., de Ridder, D.J., Tubaro, A., Turner, W.H., Pickard, R.S.: EAU guidelines on surgical treatment of urinary incontinence. Eur. Urol. 62, 1118-1129 (2012)

4. Gormley, E.A., Lightner, D.J., Burgio, K.L., Chai, T.C., Clemens, J.Q., Culkin, D.J., Das, A.K., Foster Jr, H.E., Scarpero, H.M., Tessier, C.D., Vasavada, S.P.: Diagnosis and treatment of overactive bladder (non-neurogenic) in adults: AUA/SUFU guideline. J. Urol. 188, 2455-2463 (2012)

5. National Institute for Health and Care Excellence: NICE clinical guideline 171 (CG171). Urinary incontinence: the management of urinary incontinence in women. http://www.nice.org.uk/gui dance/cg171/resources/guidance-urinary-incontinence-pdf. (2013) Accessed June 2014

6. D'Souza, A.O., Smith, M.J., Miller, L.A., Doyle, J., Ariely, R.: Persistence, adherence and switch rates among extended-release and immediate-release overactive bladder medications in a regional managed care plan. J. Manag. Care. Pharm. 14, 291-301 (2008)

7. Chapple, C., Sievert, K.D., MacDiarmid, S., Khullar, V., Radziszewski, P., Nardo, C., Thompson, C., Zhou, J., HaagMolkenteller, C.: OnabotulinumtoxinA 100 U significantly improves all idiopathic overactive bladder symptoms and quality of life in patients with overactive bladder and urinary incontinence: a randomised, double-blind, placebo-controlled trial. Eur. Urol. 64, 249-256 (2013)

8. Nitti, V.W., Dmochowski, R., Herschorn, S., Sand, P., Thompson, C., Nardo, C., Yan,X., Haag-Molkenteller, C., EMBARK Study Group: OnabotulinumtoxinA for the treatment of patients with overactive bladder and urinary incontinence: results of a phase 3, randomized, placebo controlled trial. J. Urol. 189, 2186-2193 (2013)

9. Nitti, V.W., Chapple, C., Sussman, D., Radomski, S., Sand, P., Guard, S., Nardo, C., Zhou, J., Sievert, K.D.: Long-term efficacy and safety of repeat onabotulinumtoxina treatment in overactive bladder syndrome and urinary incontinence: third interim analysis, median 2.4 year follow-up. J. Urol. 191, e400-e401 (2014)
10. Veeratterapillay, R., Harding, C., Teo, L., Vasdev, N., Abroaf, A., Dorkin, T.J., Pickard, R.S., Hasan, T., Thorpe, A.C.: Discontinuation rates and inter-injection interval for repeated intravesical botulinum toxin type A injections for detrusor overactivity. Int. J. Urol. 21, 175-178 (2014)

11. Dowson, C., Watkins, J., Khan, M.S., Dasgupta, P., Sahai, A.: Repeated botulinum toxin type A injections for refractory overactive bladder: medium-term outcomes, safety profile, and discontinuation rates. Eur. Urol. 61, 834-839 (2012)

12. Kay, S., Tolley, K., Colayco, D., Khalaf, K., Anderson, P., Globe, D.: Mapping EQ-5D utility scores from the Incontinence Quality of Life Questionnaire among patients with neurogenic and idiopathic overactive bladder. Value Health 16, 394-402 (2013)

13. Brazier, J.E., Roberts, J.: The estimation of a preference-based measure of health from the SF-12. Med. Care. 42, 851-859 (2004)

14. Cuervo, J., Castejòn, N., Khalaf, K., Waweru, C., Globe, D., Patrick, D.L.: Development of the Incontinence Utility Index: estimating population-based utilities associated with urinary problems from the Incontinence Quality of Life Questionnaire and Neurogenic Module. Health Qual. Life Outcomes. 12, 147 (2014)

15. Wu, J.M., Siddiqui, N.Y., Amundsen, C.L., Myers, E.R., Havrilesky, L.J., Visco, A.G.: Cost-effectiveness of botulinum toxin a versus anticholinergic medications for idiopathic urge incontinence. J. Urol. 181, 2181-2186 (2009)

16. Chen, H.W., Bercik, R.S., Werner, E.F., Thung, S.F.: Cost-effectiveness of percutaneous tibial nerve stimulation versus extended release tolterodine for overactive bladder. J. Urol. 187, 178-184 (2012)

17. Kim, H.S.K., Pathan, S., Habashy, D., Tse, V., Collins, R., Chan, L.: 8 year experience of OnabotulinumtoxinA (BTXA) injections for the treatment of non neurogenic overactive bladder: are repeat injections worthwhile? BJU. Int. 111, 13-119 (2013)

18. Jiménez-Cidre, M., Costa, P., Globe, D., Ng-Mak, D., Sahai, A., Smith, C.P., Tsai, K., Herschorn, S.: International Burden of Incontinence Study (IBIS): association between incontinence severity and healthcare utilization. Presented at the ICS 43rd Annual Meeting, 26-30 August, Barcelona, Spain. http://www. ics.org/Abstracts/Publish/180/000502_poster.pdf. (2013) Accessed 9 June 2014

19. East Midlands Specialized Commissioning Group: Sacral Nerve Stimulation (SNS) for Urinary Incontinence (UI). http://www. leicestercity.nhs.uk/Library/SNSUI2011v121022011.pdf. (2012) Accessed 25 June 2014

20. National Collaborating Centre for Women's and Children's Health commissioned by the National Institute for Health and Care Excellence: urinary incontinence in women: the management of urinary incontinence in women. Full guideline. http:// www.nice.org.uk/guidance/cg171/resources/cg171-urinary-incon tinence-in-women-full-guideline3. (2013) Accessed 9 June 2014

21. Aboseif, S., Tamaddon, K., Chalfin, S., Freedman, S., Kaptein, J.: Sacral neuromodulation as an effective treatment for refractory pelvic floor dysfunction. Urology 60, 52-56 (2002)

22. Janknegt, R.A., Hassouna, M.M., Siegel, S.W., Schmidt, R.A., Gajewski, J.B., Rivas, D.A., Elhilali, M.M., Milam, D.C., van Kerrebroeck, P.E., Dijkema, H.E., Nyeholt, A.A., Fall, M., Jonas, U., Catanzaro, F., Fowler, C.J., Oleson, K.A.: Long-term effectiveness of sacral nerve stimulation for refractory urge incontinence. Eur. Urol. 39, 101-106 (2001)

23. Kessler, T.M., Danuser, H., Schumacher, M., Studer, U.E., Burkhard, F.C.: Botulinum A toxin injections into the detrusor: an effective treatment in idiopathic and neurogenic detrusor overactivity? Neurourol. Urodyn. 24, 231-236 (2005)

24. Marcelissen, T.A., Leong, R.K., de Bie, R.A., van Kerrebroeck, P.E., de Wachter, S.G.: Long-term results of sacral 
neuromodulation with the tined lead procedure. J. Urol. 184, 1997-2000 (2010)

25. Siegel, S.W., Catanzaro, F., Dijkema, H.E., Elhilali, M.M., Fowler, C.J., Gajewski, J.B., Hassouna, M.M., Janknegt, R.A., Jonas, U., van Kerrebroeck, P.E., Nijeholt, A.A., Oleson, K.A., Schmidt, R.A.: Long-term results of a multicenter study on sacral nerve stimulation for treatment of urinary urge incontinence, urgency-frequency, and retention. Urology 56, 87-91 (2000)

26. van Kerrebroeck, P.E., van Voskuilen, A.C., Heesakkers, J.P., Nijholt, A.A., Siegel, S., Jonas, U., Fowler, C.J., Fall, M., Gajewski, J.B., Hassouna, M.M., Cappellano, F., Elhilali, M.M., Milam, D.F., Das, A.K., Dijkema, H.E., van den Hombergh, U.: Results of sacral neuromodulation therapy for urinary voiding dysfunction: outcomes of a prospective, worldwide clinical study. J. Urol. 178, 2029-2034 (2007)

27. Hedlund H, Schultz A, Talseth T, Tonseth K, van der Hagen A: Sacral neuromodulation in Norway: clinical experience of the first three years. Scand. J Urol Nephrol Suppl, 2002(210), 87-95 (2002)

28. NHS England: Clinical commissioning policy: sacral nerve stimulation (SNS) for faecal incontinence (Adult) (Reference: NHSE/A08/P/b). http://www.england.nhs.uk/wp-content/uploads/ 2013/08/a08-p-b.pdf. (2013) Accessed 9 June 2014

29. National Institute for Health and Care Excellence: Guide to the methods of technology appraisal. http://www.nice.org.uk/article/ pmg9/chapter/Foreword. (2013) Accessed 9 June 2014

30. Sonnenberg, F.A., Beck, J.R.: Markov models in medical decision making: a practical guide. Med. Decis. Making. 13, 322-338 (1993)

31. Claxton, K., Martin, S., Soares, M., Rice, N., Spackman, E., Hinde, S., Devlin, N., Smith, P.C., Sculpher, M.: Methods for the estimation of the NICE cost effectiveness threshold. http://www. york.ac.uk/media/che/documents/reports/resubmitted_report.pdf. (2013) Accessed 9 June 2014

32. Arlandis, S., Castro, D., Errando, C., Fernandez, E., Jimenez, M., Gonzalez, P., Crespo, C., Staeuble, F., Rodriguez, J.M., Brosa, M.: Cost-effectiveness of sacral neuromodulation compared to botulinum neurotoxin a or continued medical management in refractory overactive bladder. Value Health 14, 219-228 (2011)

33. BOTOX summary of product characteristics. http://www.medi cines.org.uk/emc/medicine/112. Last updated 28 January 2014. Accessed 10 February 2014

34. Finkelstein, M.M., Skelly, J., Kaczorowski, J., Swanson, G.: Incontinence Quality of Life instrument in a survey of primary care physicians. J. Fam. Pract. 51, 952 (2002)

35. Oh, S.J., Ku, J.H.: Is a generic Quality of Life instrument helpful for evaluating women with urinary incontinence? Qual. Life. Res. 15, 493-501 (2006)

36. Haywood, K.L., Garratt, A.M., Lall, R., Smith, J.F., Lamb, S.E.: EuroQol EQ-5D and condition-specific measures of health outcome in women with urinary incontinence: reliability, validity and responsiveness. Qual. Life. Res. 17, 475-483 (2008)
37. Papaioannou, D., Brazier, J., Parry, G.: How valid and responsive are generic health status measures, such as EQ-5D and SF-36, in schizophrenia? A systematic review. Value Health 14, 907-920 (2011)

38. Davis, S., Wailoo, A.: A review of the psychometric performance of the EQ-5D in people with urinary incontinence. Health Qual. Life Outcomes 11, 20 (2013)

39. Patrick, D.L., Khalaf, K.M., Dmochowski, R., Kowalski, J.W., Globe, D.R.: Psychometric performance of the incontinence quality-of-life questionnaire among patients with overactive bladder and urinary incontinence. Clin. Ther. 35, 836-845 (2013)

40. Farage, M.A., Miller, K.W., Berardesca, E., Maibach, H.I.: Incontinence in the aged: contact dermatitis and other cutaneous consequences. Contact Dermatitis. 57, 211-217 (2007)

41. Gray, M.: Incontinence-related skin damage: essential knowledge. Ostomy Wound Manage. 53, 28-32 (2007)

42. Chiarelli, P.E., Mackenzie, L.A., Osmotherly, P.G.: Urinary incontinence is associated with an increase in falls: a systematic review. Aust. J. Physiother. 55, 89-95 (2009)

43. Wagner, T.H., Hu, T.W., Bentkover, J., LeBlanc, K., Stewart, W., Corey, R., Zhou, Z., Hunt, T.: Health-related consequences of overactive bladder. Am. J. Manag. Care. 8, S598-S607 (2002)

44. Kraus, S.R., Bavendam, T., Brake, T., Griebling, T.L.: Vulnerable elderly patients and overactive bladder syndrome. Drugs Aging. 27, 697-713 (2010)

45. Mangera, A., Apostolidis, A., Andersson, K.E., Dasgupta, P., Giannantoni, A., Roehrborn, C., Novara, G., Chapple, C.: An updated systematic review and statistical comparison of standardised mean outcomes for the use of botulinum toxin in the management of lower urinary tract disorders. Eur. Urol. 65, 981-990 (2014)

46. British National Formulary: British National Formulary 65 . Pharmaceutical Press, London (2013)

47. Department of Health: NHS reference costs. Financial year 2011-2012. https://www.gov.uk/government/publications/nhsreference-costs-financial-year-2011-to-2012. Accessed 9 June 2014

48. National Schedule of Reference Costs. NHS Trust (2010-2011). https://www.gov.uk/government/publications/2010-11-referencecosts-publication. Accessed 9 June 2014

49. PSSRU: personal social service research unit: Unit costs of health and social care. http://www.pssru.ac.uk/project-pages/unit-costs/ 2012/index.php. (2012) Accessed 9 June 2014

50. OPCS classification of interventions and procedures. www.nice. org.uk/media/075/86/OPCSReportsSeptember2012.pdf. Accessed 9 June 2014

51. National tariff information workbook (including non-mandatory prices) (2014/15). https://www.gov.uk/government/publications/ national-tariff-payment-system-2014-to-2015. Accessed 9 June 2014 